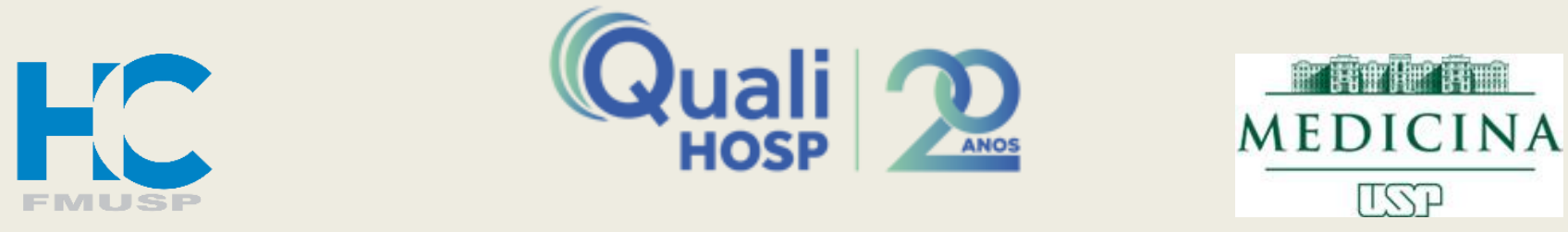

\title{
A ARQUITETURA HOSPITALAR COMO ALIADA NA MELHORIA DOS INDICADORES ASSISTENCIAIS
}

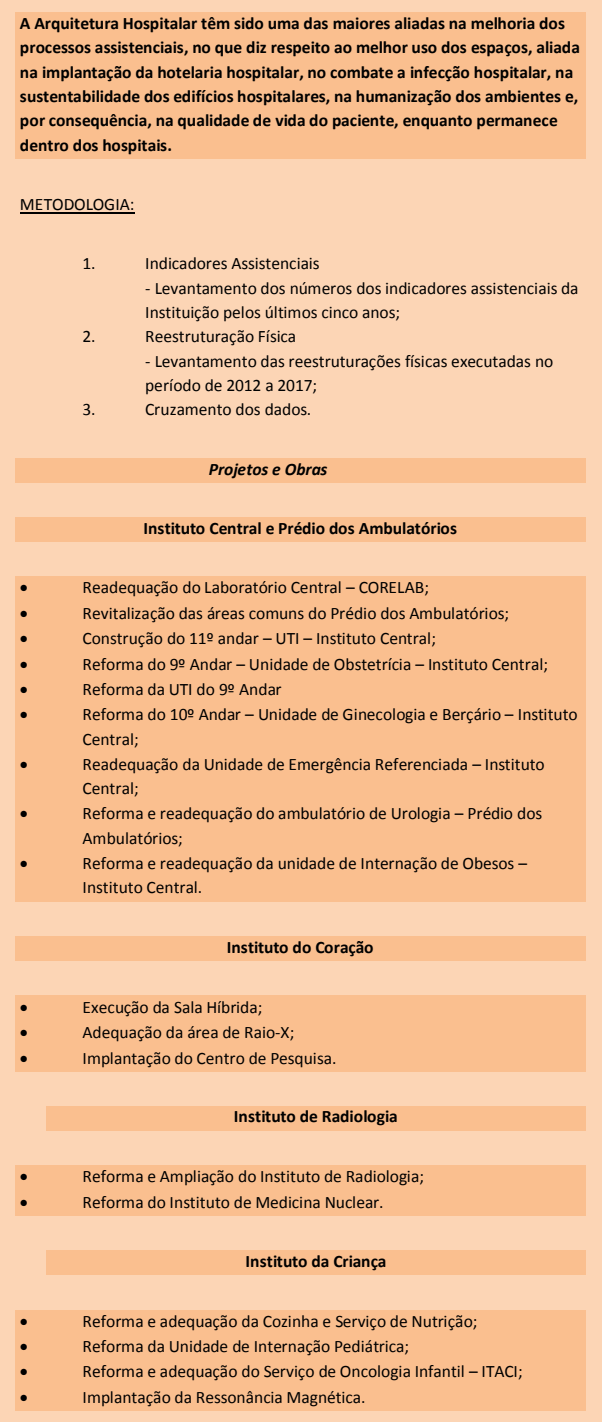

OBRA DE REESTRUTURAÇÃO DA UTI - $9^{\circ}$ ANDAR INSTITUTO CENTRAL
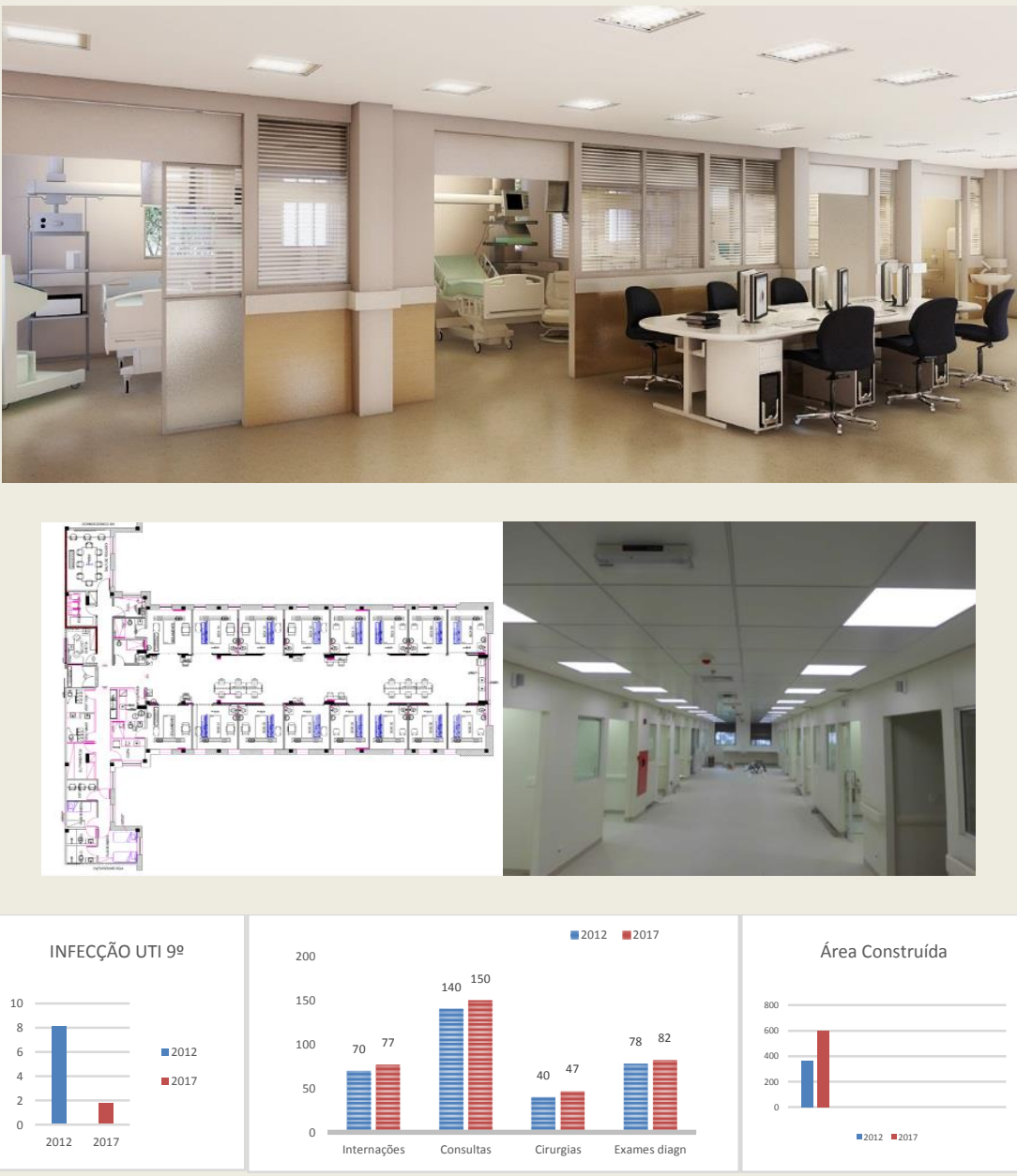

\begin{tabular}{lccc}
\hline Indicadores & 2012 & 2017 & Porcentagem \\
\hline № de Internações & 70,2 mil & 77 mil & Aumento de $10 \%$ \\
\hline № de Consultas Ambulatoriais & 1,4 milhões & 1,5 milhões & Aumento de $8 \%$ \\
\hline № de Cirurgias & 40 mil & 47 mil & Aumento de $17 \%$ \\
\hline № de Exames de Diagnóstico por Imagem & 782 mil & 824 mil & Aumento de $6 \%$ \\
\hline Área Construída & 362 mil & 600 mil & Aumento de $65 \%$ \\
\hline Infecção Hospitalar UTI 90 Andar & 8,1 & 1,8 & Redução de $78 \%$
\end{tabular}

CONCLUSÃO:

Após a análise dos dados apresentados, concluímos que, embora o crescimento da área física e do número de leitos não seja proporcional ao aumento dos números apontados nos indicadores assistenciais, houve a constatação de que a reestruturaç̃o físiç é importante para a melhoria da qualidade de vida do paciente, no que diz respeito ao aumento da capacidade instalada do hospital, na melhoria do atendimento, aumento da segurança do paciente e na redução do índice de Infecção Hospitalar. 